\title{
Trabalho precário e precarização institucional nos Estados Unidos"
}

\section{Resumo}

Este artigo analisa as bases institucionais do trabalho precário nos Estados Unidos através de um duplo processo de precarização: da relação contratual tradicional e, dada a fragmentação do quadro institucional, a inadaptação da lei trabalhista dos Estados Unidos. O texto procura enfatizar a importância do estatuto do trabalhador - a relação contratual de emprego - para o acesso do mesmo aos direitos e benefícios sociais básicos. Os efeitos da recente crise econômica e a resposta das políticas públicas são discutidos na conclusão.

Palavras-chave: Direito trabalhista. Direitos sociais. Movimento operário. Status salarial. Trabalhadores precários. Seguro social.

* Université Paris Est Créteil.

** Tradução de Patrícia C. R. Reuillard (UFRGS). 


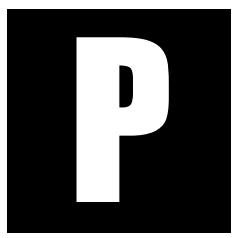

ropomos uma reflexão sobre a relação entre as instituições políticas e a precarização das formas de emprego nos Estados Unidos. O surgimento do trabalho precário revelou a ausência de um princípio unificador comumente admitido no direito trabalhista e as consequências sociais dessa fragmentação. Como sabemos, o direito trabalhista desempenha um papel fundamental e complexo no desenvolvimento do trabalho precário em todos os países (HOUSEMAN; OSAWA, 2003).

O que surpreende o observador é a complexidade do funcionamento do sistema jurídico estadunidense. Observa-se a coexistência de instâncias federais e estatais ao lado do direito jurisprudencial da common law, em cujo âmbito a prática contratual permitiu a obtenção de condições muito vantajosas para alguns empregados. É igualmente difícil, para os observadores estrangeiros, captar noções próprias a essa cultura política: como transpor para outro sistema jurídico a representação do empregado (employee), do direito social (Social Security), ou a noção jurídica de equidade (fairness)?

Aqui o termo trabalho precário é preferido ao de trabalho "não padrão". Em um país europeu, como a França, o padrão é tradicionalmente o contrato de duração indeterminada (CDI), forma jurídica de direito comum do contrato de trabalho. Portanto, as formas particulares do emprego foram regulamentadas, a partir dos anos 1970, tomando como referência o CDI, o trabalho interino (emprego temporário ou temps, em inglês), o CDD (contrato de duração determinada) e o tempo parcial (LEFRESNE, 2006). Este é o padrão a partir do qual se pode tentar avaliar o grau de desconstrução das normas e de precarização dos trabalhadores/trabalhadoras. Nos Estados Unidos, a situação é diferente. O que se denomina status salarial nunca foi objeto de padronização institucional nem foi estendido ao conjunto dos trabalhadores, mas foi construído por uma com- 
binação de elementos heterogêneos: normas jurídicas, negociações coletivas, práticas de gestão dos recursos humanos das grandes empresas. De fato, jamais existiu nesse país, como na França, um ideal de constituição de uma classe social homogênea beneficiando-se de direitos iguais, ou uma vontade coletiva de redistribuição em escala nacional do custo social ou dos riscos trabalhistas (PELISSIER; SUPIOT, 2006). Assim, o lugar do contrato social e o papel do movimento sindical são mais determinantes do que geralmente se crê. Utilizamos o termo trabalho precário porque a precariedade é realmente o traço característico que marca a experiência do conjunto dos trabalhadores dessa categoria, criando um fenômeno social. Isso é tanto mais verdade nesse país - que não oferece proteção universal pública, principalmente em matéria de plano de saúde - porque é o status salarial que tradicionalmente dá acesso a essa vantagem social fundamental. Vamos levantar hipóteses sobre o impacto, no mercado do emprego estadunidense, da lei histórica de 2010 sobre o plano de saúde.

Começaremos por um estudo preliminar das instituições de direito trabalhista estadunidense. Essa retomada possibilitará avaliar melhor a dificuldade enfrentada por esse sistema jurídico, concebido para os empregados em tempo integral, para proteger os trabalhadores precários diante da multiplicação das construções não-salariais e devido às suas próprias insuficiências. Veremos, em seguida, o lugar e os limites do status salarial, concluindo com um rápido levantamento da situação atual. Buscamos, acima de tudo, estudar o mercado de trabalho e de emprego às vésperas da crise do mercado de emprego, já em andamento quando estourou a crise financeira de 2008.

A análise inscreve-se no conceito de precarização social (APPAY, 2005), que compara o duplo processo de precarização econômica e de institucionalização da instabilidade. Nos Estados Unidos, qualquer questionamento do dispositivo das negociações coletivas, mecanismo princi- 
pal de redistribuição, remete a aquisição dos benefícios sociais e a regulamentação da relação trabalhista às instituições políticas e, em última instância, ao trabalhador individual.

\section{Um enquadramento jurídico fragmentado}

Nos Estados Unidos, o trabalho precário nunca foi objeto de uma legislação nacional global: ele é simplesmente regulamentado por uma adaptação progressiva do direito trabalhista. Ora, longe de constituir um direito globalmente coerente, resulta de uma acumulação de práticas coletivas, de dispositivos legislativos, de regras jurisprudenciais, que resultam dos períodos históricos sucessivos e obedecem a lógicas diferentes. Apresentamos aqui os componentes mais significativos do direito trabalhista estadunidense, chamado de labor and employment law, assim como as condições de surgimento do trabalho precário. Este exame permitirá uma melhor avaliação das consequências do questionamento da relação empregado-empregador.

Os dois componentes maiores do direito trabalhista e o surgimento do trabalho precário

A Labor Law propriamente dita refere-se aos direitos coletivos dos empregados, obtidos na época do New Deal' ${ }^{1}$, em particular ao regime das negociações coletivas. No que tange ao Estado social, o Social Security Act (1935) implantou o embrião de um Estado-providência. Os direitos eram concebidos como um patamar: seguro-desemprego, auxílio social às famílias pobres - chamado de welfare - e, para a aposentadoria, a

$1 \mathrm{O}$ New Deal refere-se à política intervencionista nas áreas econômicas e sociais, aplicada entre 1933 e 1938, pelo presidente democrata Franklin Delano Roosevelt para enfrentar as consequências da Grande Depressão nos Estados Unidos. 
Social Security, única caixa nacional abrangendo o conjunto dos trabalhadores americanos, inclusive os independentes, equivalente ao seguro de velhice europeu. O Fair Labor Standards Act (1938) estabeleceu as normas mínimas em matéria de condições de trabalho - semana de quarenta horas com pagamento das horas extras, salário mínimo, idade mínima do trabalhador. Implantando um controle estatal direto sobre a relação do emprego, o FLSA adotava o consenso da época em torno dos direitos coletivos dos empregados.

No cerne do dispositivo, encontra-se o sistema de obtenção contratual de benefícios e garantias. Gerindo indiretamente as relações industriais, o Estado contentou-se em estabelecer seu enquadramento jurídico (Wagner $A c t^{2}$, 1935). Os parceiros negociam as garantias no âmbito de contratos privados da empresa: fundos de pensão como complemento ao seguro público de velhice da Social Security, benefícios não previstos pela legislação, como plano de saúde e férias, condições de trabalho e regulamentação dos litígios (grievance procedure). A escolha de um sistema contratual privado correspondia às tradições do sindicalismo anglo-saxão e mais particularmente estadunidense, pela gestão legal das vantagens econômicas (business unionism). Esse modelo era igualmente uma escolha política. Em primeiro lugar, o governo Roosevelt limitou, com seu New Deal, a extensão do Estado-providência, recusando a inclusão do seguro-saúde. Após a Guerra, durante as conferências sobre a Declaração Universal dos Direitos Humanos, na Europa, os delegados estadunidenses defenderam o modelo das negociações coletivas, opondo-se a uma maioria que preconizava um papel central ao Estado (GOTTSHALK, 2000; JACOBY, 2001).

2 Segundo o senador Robert Wagner, seu criador, essa lei de 1935 sobre as liberdades sindicais intitula-se oficialmente Lei Nacional sobre as Relações Industriais (National Labor Relations Act). Essas liberdades foram em seguida severamente restritas, por iniciativa dos representantes eleitos do Partido Republicano e do Taft-Hartley Act de 1947. Originalmente limitadas ao setor privado, o direito de exercício das negociações coletivas foi estendido ao setor público nacional no mandato do presidente democrata Kennedy em 1962. 
Nos anos 1960, ocorreu a "revolução dos direitos". Trata-se de direitos individuais atribuídos por lei sobre os direitos cívicos de 1964 contra a discriminação e suas decorrências. Assim, o que se denominaria Employment Law introduziu uma regulamentação pública nacional dos termos do contrato individual e das condições de trabalho. Ela gerou direitos individuais para os empregados, mas, diferentemente dos direitos sociais coletivos oriundos das lutas operárias do período acima citado, eles levaram a uma certa transferência das lutas das fábricas para os tribunais. Essa intervenção direta do Estado nacional aplica-se ao conjunto das empresas presentes no território e a todos os empregados, inclusive aqueles não cobertos pelos contratos coletivos. De fato, em uma concessão feita aos sulistas do Partido Democrata, que ameaçavam impedir sua aprovação, a lei Wagner havia excluído do direito às negociações coletivas os trabalhadores agrícolas e domésticos, frequentemente negros e imigrantes. As insuficiências do New Deal, sua incapacidade para garantir direitos coletivos de classe em seu conjunto, abriram assim o caminho para as leis sobre os direitos cívicos individuais.

Com efeito, no Título VII, a lei sobre os direitos cívicos de 1964 proibiu qualquer discriminação em função da cor da pele, das crenças religiosas, da proveniência nacional ou do sexo, em matéria de contratação, de carreira - por exemplo, de acesso à formação - ou de demissão. A nova concepção dos direitos serviu em seguida para proteger outras categorias de empregados: os empregados com mais de 40 anos, os deficientes, as mulheres grávidas ${ }^{3}$. Por outro lado, implantaram-se políticas de tratamento preferencial de certos grupos (Affirmative Action Law), constituídas por um processo interativo entre leis, ação governamental e doutrina jurisprudencial, sobretudo por meio das grandes sentenças da Suprema Corte.

3 Age Discrimination Employment Act (ADEA, 1967), Pregnancy Discrimination Act (PDA, 1977), Americans with Disabilities Act (ADA, 1990). 
Uma segunda categoria de leis nacionais atinentes ao Employment Law introduziu uma regulamentação mínima das condições de trabalho (minimum workplace requirements). Trata-se da criação de uma inspeção trabalhista (OSHA) e da obrigação de aviso-prévio em caso de demissões em massa (WARN). Os empregados obtiveram certo controle sobre os planos de fundos de pensão, com uma garantia sobre seu financiamento (ERISA), e uma licença excepcional sem vencimentos em caso de doença grave na família de até doze semanas por ano (FMLA) ${ }^{4}$.

\section{O surgimento do trabalho precário}

A partir dos anos 1970, assiste-se ao declínio do modelo das relações de trabalho decorrente do New Deal e ao surgimento do trabalho precário. Ambos procedem de um mesmo movimento (BEFORT, 2003): o patronato compreendeu o interesse das novas formas de emprego flexível em sua resistência às restrições impostas às suas prerrogativas de gestão.

O desenvolvimento da precariedade na indústria alimentou-se das ondas de reestruturações, de deslocalizações e de desregulamentação (transporte aéreo, rodoviário), assim como da lógica financeira subjacente (GONOS, 1997). Entre 1980 e 1988, o índice de empregos precários passou de $26,7 \%$ para $30,1 \%$ da população ativa - um crescimento $75 \%$ mais rápido do que o do emprego - e depois continuou a crescer, nos cinco anos seguintes, em um ritmo menos acelerado. $\mathrm{O}$ apelo às agências de trabalho interino (temp agency) aumentou mais rapidamente (BELOUS, 1995; MIDDELTON, 1996) do que o trabalho em tempo parcial que, constituindo o segmento mais importante dos empregos precários, terminou por representar cerca de um trabalhador em cinco (18\%). A pro-

4 Occupational Safety and Health Administration (OSHA, 1970), Worker Adjustment and Retraining Notification (WARN, 1988), Employee Retirement Income Security Act (ERISA, 1974), Family and Medical Leave Act (FMLA, 1993). 
porção de empregos precários entre os operários (blue collar) progrediu, principalmente devido a uma multiplicação dos trabalhadores interinos na produção. Em um contexto de escalada do setor terciário - dois terços dos 15,2 milhões de empregos criados nesses oito anos -, uma parte do crescimento correspondeu à terceirização dos empregos da indústria. Nos serviços à empresa (business services), constatou-se, em vinte e cinco anos, um faturamento vinte vezes maior em proveito de consultores externos, engenheiros, informatas, técnicos ${ }^{5}$.

A proporção de trabalhadores precários estabilizou-se de meados dos anos 1990 até 2005 em cerca de 30\% da população ativa ${ }^{6}$ e teve uma leve baixa durante a expansão econômica do final dos anos 1990, idade do ouro da "máquina americana de criar empregos", salvo no caso do emprego temporário, que continuou a progredir. Em certas categorias, o índice é relativamente pouco elevado - a cifra para o interino antes de 2005 era três vezes mais alta na França, sete vezes mais na Espanha. Isso corresponde ao comportamento estrutural clássico de um país que enfrenta pouco desemprego, tem crescimento rápido do emprego e com

5 O número de trabalhadores temporários (CDD) de 34.000 em 1972 a 707.000 em 1997. O faturamento na consultoria passou de 53 milhões a 1,3 bilhões entre 1972 e 1997. "LowSkill Workers and Employers Benefit from Temporary Employment During Difficult Economic Times", PR Newswire, (20 de dezembro de 2001).

6 A cifra de 30,1\% em 1995, segundo Belous (1995), considera as categorias elencadas pelo escritório americano sobre as estatísticas do trabalho, às quais se acrescenta o trabalho em tempo parcial, e leva em conta excluídos das estatísticas. The State of Working America (2006/2007) cita 32,2\% em 1995 e 31,6\% em 2005.

O Bureau of Labor Statistiques contabiliza 15 \% de trabalhadores "não padrão", divididos em duas grandes categorias. Primeiramente, os contingent workers, que não "esperam que seu emprego seja de duração indeterminada ou que declaram que seu emprego é temporário" são, em fevereiro de 2005, cerca de $4 \%$ da mão-de-obra. A seguir, registram-se 11,3 \% de trabalhadores em situações de emprego qualificado como alternativo (alternative work arrangements): 7,4 \% de trabalhadores independentes (independent contracters), 1,8 \% de trabaIhadores por tarefa (on call), interinos em agência $(0,9 \%)$ ou por intermédio de uma empresa contratada (0,6 \%). Monthly Labor Review, (août 2005).

Contavam-se 17,4\% da população trabalhando em tempo parcial em 2005. 
poucas restrições regulamentares, sobretudo no que diz respeito às demissões (HOUSEMAN; OSAWA, 2003).

Essa fragilidade regulamentar não impediu o patronato de apropriar-se do trabalho precário como uma estratégia de resposta às pressões institucionais ou econômicas que lhe foram impostas, tanto no terreno jurídico quanto no das negociações coletivas. Ele tinha as mãos livres, contrariamente ao caso europeu, onde leis foram criadas para garantir aos trabalhadores precários a igualdade de tratamento dos empregados com CDI em matéria de salários e de proteção social (SCHÖMANN; SCHÖMANN, 2003). Durante os oito anos de progressão rápida do trabalho precário dos anos 1980, pode-se constatar, nos Estados Unidos, que as agências de trabalho interino tiveram uma progressão muito significativa, até $20 \%$ a mais em termos de efetivos, nos Estados em que a lei e a jurisprudência asseguraram uma aplicação rigorosa da regulamentação pública em favor dos empregados de tempo integral, principalmente a proibição da discriminação (AUTOR, 2003).

A precarização pesou da mesma maneira na instituição contratual: a questão tange ao status salarial de employee em tempo integral com os benefícios atinentes, principalmente o plano de saúde. A trabalhadora sem acesso aos benefícios sociais em razão de seu emprego precário dependia daqueles usufruídos pelo marido. De fato, as primeiras atingidas por esse fenômeno foram as mulheres. Sua entrada em massa no mercado do trabalho nessa época relacionou-se à expansão dos serviços, com 26,9\% de efetivos no setor da distribuição, conhecido por seus empregos com pequena cobertura social (PERUSEK, WORCESTER, 1995). Para Richard Belous, tratava-se de uma "nova era", em que a família se afirmou nas relações de trabalho como a instituição de redistribuição dos benefícios sociais ligados ao emprego (HANDELMAN, 1995). O custo de trabalho extra suportado pelo empregador principal (family converage) 
incitou-o, por sua vez, a apelar para empregos precários. Outros fenômenos contribuíram para a desestabilização do contrato coletivo. Desde 1979, o Sindicato dos Trabalhadores Automobilísticos UAW (United Auto Workers) negociava na Chrysler sob a égide do Estado, que se apresentava como garantia, os contratos denominados de concessões, em nome da "preservação do emprego industrial americano". Os givebacks, redução líquida dos salários e dos benefícios sociais, minavam as fundações do mecanismo de redistribuição negociada que havia impulsionado os operários sindicalizados e suas famílias para a classe média. Apresentadas como uma medida temporária de emergência, as concessões foram-se multiplicando em futuras negociações coletivas até os dias de hoje.

Abriu-se uma brecha no contrato implícito interno à empresa, que garantia o emprego a longo prazo acompanhado de benefícios, ele próprio fundamento do contrato social americano (MOSS; SALZMAN; TILLY; 2000). Embora a proporção dos empregados cobertos por contratos coletivos jamais tivesse ultrapassado um terço, os ganhos substanciais obtidos em proveito dos sindicalizados tiveram um efeito cascata sobre o conjunto do salariado. Ainda em 1988, 89\% da população ativa beneficiavam-se de uma cobertura médica e $68 \%$ de uma aposentadoria (52\% e $49 \%$ em 2003) (WIATROWSKI, 2004). O "contrato social" do pós-guerra trazia a estabilidade: por buscarem uma mão-de-obra permanente em condições de garantir a continuidade do crescimento, os empregadores aceitavam conceder segurança e um emprego decente. Esse processo de extensão dos benefícios a toda a população ativa, ultrapassando os setores sindicalizados, começara a diminuir desde o final dos anos 1950 e terminou nos anos 1980. O advento dessa nova era em que cresciam as desigualdades na sociedade estadunidense correspondeu à virada na relação de força social em detrimento dos sindicatos (DERICKSON, 1994; HARRISON, 1994). 
Uma dinâmica de precarização opunha-se ao emprego salarial. Quanto mais as famílias dependiam dos pacotes de remuneração com benefícios sociais para preservarem seu nível de vida, mais o status salarial em tempo integral afirmava-se, mas ao mesmo tempo mais pressão se exercia sobre os empresários que concediam esse status. Todo questionamento do dispositivo das negociações coletivas remetia a aquisição dos benefícios sociais e a regulamentação da relação de trabalho às instituições políticas e, haja vista sua fragmentação, como a falta de recursos atribuídos à aplicação dos dispositivos existentes, ao trabalhador individual e sua família. O trabalho precário modificou assim a relação tradicional entre empregado e empregador e, de modo mais amplo, o sistema estadunidense de redistribuição (GONOS, 2006; STONE, 2004).

\section{Uma fragmentação institucional dos direitos}

\section{A importância do status salarial}

O desenvolvimento do trabalho precário revelou a ausência de um princípio unificador comumente admitido no direito trabalhista e nas instituições sociais. A precariedade do emprego atinge o âmago daquilo que permite aos trabalhadores americanos ter acesso a um emprego, ou seja, o status de empregado (employee). A existência de um status salarial reveste-se de uma significação muito particular nos Estados Unidos: é a peça-chave do mercado de trabalho e do sistema de redistribuição da riqueza, já que esse sistema está ligado ao emprego. A atribuição de direitos, proteções e benefícios, simultaneamente legislativos, contratuais e jurisprudenciais, define-se de acordo com cada relação salarial. Neste país, onde os custos do seguro social jamais foram estendidos a toda a nação, a questão apresenta-se como eminentemente política: todo en- 
fraquecimento do status de empregado permanente - que trabalha em tempo integral para o mesmo empregador - acarreta uma diminuição do bem-estar social de todos.

É interesse financeiro do patrão não conceder o status de empregado. A ausência de status permite evitar o pagamento dos encargos às caixas nacionais, uma diminuição de $20 \%$ a $40 \%$ do custo salarial ${ }^{7}$. Faz-se economia por meio da flexibilidade na utilização da mão-de-obra, mas também do abuso na segurança e na higiene, do não-pagamento de horas-extras ou de indenizações de acidente do trabalho, da não-regularização dos imigrantes. Revelador disso é a situação dos trabalhadores empregados por dia (DERICKSON, 1994; CHAUVIN, 2010), cada vez mais numerosos na construção civil, na agricultura, na vigilância, nos empregos a domicílio, bem como a das interinas deslocadas de um escritório a outro, que sofrem assédio devido à brevidade de sua passagem em cada lugar.

O questionamento do status salarial assume múltiplas formas, começando por uma definição cada vez mais restrita do grupo social dos empregados. Somente os trabalhadores que não têm responsabilidade decisória ou propositiva no trabalho podem beneficiar-se de direitos de negociação, de ações de reivindicação, de contratos coletivos; esse campo de sindicalização reduzido exclui os "executivos" (os supervisors e os managers) e também os técnicos ${ }^{8}$. Definições cada vez mais limitadas foram-se sucedendo: as auxiliares de pré-escola e os auxiliares de cozinha (inclusive no fast-food) foram eliminados da categoria, sob a influência da administração

\footnotetext{
7 Os patrões americanos pagam a parte patronal e retiram do salário a parte salarial. Os encargos federais das payroll taxes para um empregado, $12,3 \%$, compreendem as cotizações para aposentadoria e indenizações aos trabalhadores deficientes para o sistema de Social Security, a Federal Insurance Contributions Act (FICA), e para a caixa do desemprego, a Federal Unemployment Tax Act (FUTA).

8 Contam-se 37,7\% de sindicalização da população ativa em 1954 e, em 2005, aproximadamente 12,5 , dos quais $7,4 \%$ no setor privado. No público, a noção de executivo não se aplica.
} 
G.W. Bush, em decorrência de decisões da Comissão Nacional de Arbitragem das Relações Industriais (NLRB) e da Corte Suprema ${ }^{9}$.

A ambiguidade sobre a definição do status jurídico dos empregados, gerador de direitos, abre uma brecha que os patrões ficam tentados a explorar em seu benefício. Ao classificar seus agentes de instalação e de manutenção como "executivos", uma empresa como a IBM contestou o pagamento de dezenas de milhares de horas-extras além das 40 horas. A Microsoft, por sua vez, no caso Vizcaino (1997), tentou impor o status de trabalhador independente aos Permatemps, técnicos qualificados realizando as mesmas funções que seus homólogos permanentes. Um tribunal federal atribuiu-lhes o status salarial com acesso aos fundos de pensão e pagamento dos retroativos pela empresa ao Estado. Resta que a classificação abusiva dos empregados como trabalhadores independentes está em expansão, tendo progredido mais de 20\% entre 2001 e 2005: até 30\% das empresas, conforme o Estado da federação, estavam implicadas (RUCKELHOUS, 2007). Leis locais tentam, com dificuldade, remediar a essa situação por meio de sanções fiscais (Illinois, Novo México) ou pela implantação de uma comissão de inquérito a fim de medir a extensão do fenômeno (New Hampshire). Comissões do Congresso constataram classificações abusivas dos empregados como trabalhadores independentes, mas projetos de lei sofreram forte oposição das associações patronais (RUCKELHOUS, jul. 2008).

Por outro lado, a multiplicação das composições jurídicas facilita a "terceirização" dos custos e das responsabilidades acarretada pela contratação de empregados. Além dos trabalhadores independentes, desenvolve-se a terceirização de serviços para franquias, para trabalhadores com contrato de longa duração postos à disposição por uma agência (leasing) ou por uma PEO (professional employer organization) (CARLSON, 2001).

9 NLRB c. Kentucky River Community Care, Inc, 532 U.S. 706, 2001 e Caso Oakwood Healthcare, Inc., 348 NLRB 37, 29/09/2006. NLRB (3 de outubro de 2006). 
O status salarial é enfraquecido pela existência de definições variáveis conforme a lei federal. Julgado de acordo com uma multiplicidade de critérios, um mesmo indivíduo pode ser descartado de um fundo de pensão com proteção sob o regime da ERISA ${ }^{10}$, ainda que se beneficie da semana de quarenta horas ${ }^{11}$. Em todos os casos, a exclusão dos trabalhadores precários dos direitos sociais decorre do fato de que essa legislação é concebida para os empregados permanentes. Em matéria de aposentadoria, não é fácil contabilizar as mil horas anuais que permitem cotizar para um fundo de pensão. Mesmo os empregados permanentes devem atingir o prazo de cinco anos, necessário para poder ter direitos ou usufruir de garantias públicas; razão do destino dos empregados da Enron ${ }^{12}$, que perderam seus direitos. A organização do tempo de trabalho abaixo das 35 horas obrigatórias por semana para usufruir os benefícios de um empregado em tempo integral é corrente no setor de distribuição (WALMART; LICHTENSTEIN, 2005) e de restauração.

A fragmentação traduz-se, também, pela instauração de patamares quanto ao número de empregados que trabalham em tempo integral em uma empresa para que eles próprios possam usufruir os direitos atinentes ao status. A lei contra a discriminação de idade aplica-se às empresas de

10 Nationwide Mutual Insurance. c. Darden (1992). Nesse julgamento, a Suprema Corte decidiu, no que diz respeito às leis federais que não oferecem definição precisa do empregado em relação ao trabalhador independente, que se deve julgar a partir do critério estreito do vínculo de subordinação, a norma da "common law...".

11 A lei sobre a regulamentação do trabalho de 1938 adota uma definição ampla da palavra "employee", baseada na ideia de dependência financeira do empregado em relação ao emprego considerado. "What is an employee?", Monthly Labor Review (janeiro de 2002).

$12 \mathrm{O}$ caso Enron levou a uma das maiores falências da história dos Estados Unidos em dezembro de 2001. Essa empresa de energia sofreu perdas ocasionadas por suas operações especulativas no mercado da eletricidade, amplamente relacionadas com a privatização dos distribuidores de corrente no Estado da Califórnia. Cerca de 5.000 empregados foram demitidos, sendo que um bom número deles não tinha condições de atingir a aposentadoria para a qual havia contribuído. Os dirigentes principais foram condenados por fraude e complô depois disso, entre outros, por terem vendido suas próprias ações e recuperado seus ganhos a tempo. Essa falência acarretou a do escritório de auditoria de Arthur Anderson, encarregado de suas contas. 
20 empregados. Abaixo de 15 empregados, não se aplica o Título VII da lei sobre os direitos cívicos, que torna ilegal a discriminação (racial, étnica, de gênero), o que vulnerabiliza particularmente a mão-de-obra das pequenas empresas. Um outro exemplo: são necessários mais de 100 empregados para que se aplique a lei do aviso-prévio em caso de demissões coletivas; esse aviso-prévio, que é de apenas seis semanas, não se acompanha de nenhuma restrição em matéria de plano social. A última lei nacional de criação de direitos sociais - a licença excepcional sem vencimentos em caso de doença grave na família (Family and Medical Leave Act 1993) - marcou um avanço, mas a metade dos empregados americanos não se beneficia dela, pois não tem meios para parar de trabalhar, não alcançando as 25 horas semanais exigidas (1.250 horas ao ano) ou não trabalhando para um empregador com ao menos 50 empregados).

A obrigação de um patamar mínimo de efetivos permanentes incita à manipulação na maneira de contabilizá-los: em cada dez empresas, sete declaram ter transformado empregos permanentes em precários, quase a metade confessa ter manipulado os dados para evitar o pagamento dos benefícios sociais (COHANY, 1996, American Management Association, 1999). Quanto às quarenta horas semanais ou aos acidentes de trabalho, essas leis federais não são submetidas a patamares e só se aplicam às empresas que realizam comércio interestatal, o que deixa efetivamente de lado os empregados das pequenas agências de trabalho interino (STONE, 2006).

Quando os trabalhadores têm certos direitos, diante da multiplicação das situações jurídicas, é preciso determinar qual dos empregadores é responsável. Dentre os trabalhadores não-padrão, contam-se, de um lado, aqueles classificados como funcionários do empregador ao qual fornecem um trabalho de tempo parcial, de contratação temporária direta, de teletrabalho ou de trabalho por tarefa: estes são mais ou menos assimiláveis aos empregados permanentes (BELOUS, 1994; MIDDLETON, 1995). De 
outro lado, existem os trabalhadores interinos, com contrato de duração mais ou menos longa por intermédio de uma agência ou trabalhando diretamente em um serviço terceirizado. A agência que fornece o serviço - Manpower, Kelly ou qualquer empresa subcontratada - é o empregador principal em matéria de pagamento do salário mínimo e das horas extras. A empresa que recorre ao serviço o é quando se trata de acidente ocorrido no âmbito do trabalho ou diretamente relacionado a este (arising out o for in the course of employment $\left.{ }^{13}\right)$. Em inúmeras situações, os tribunais reconhecem uma "responsabilidade conjunta" (joint employer responsability). Ora, em caso de problema, a responsabilidade pode ser objeto de litígio e ser contornada por construções jurídicas complexas, como a subcontratação "em cascata" (MIDDLETON, 1995; STONE, 2006). Embora o Estado americano tenha adotado, desde 1988, normas de responsabilidade conjunta contra a discriminação e o assédio sexual para as trabaIhadoras mais precárias, na realidade, os tribunais não entram em acordo sobre sua aplicação. E é evidentemente mais fácil transferir o trabalhador do que resolver o problema, e é muito difícil para a trabalhadora precária provar um tratamento discriminatório (MERCHANT, 2005).

A regulamentação pública é entravada por carência de meios de aplicação. No que respeita à agência da inspeção trabalhista OSHA (Occupational Health and Safety Administration), embora o índice e a gravidade dos acidentes se mostrassem em baixa, a evolução limitava-se às indústrias em que a agência concentrava seus esforços; em 2003, ela controlava cada empresa apenas a cada 107 anos. Os programas voluntários de proteção (Voluntary Protection Programs VPP) estabelecem uma relação de cooperação entre o Estado e empregadores julgados responsáveis, em condições de aplicar as normas de segurança e de higiene.

13 Disponível em: < http://definitions.uslegal.com/a/arising-out-of-and-in-the-course-of-employment/>. 
Porém, o próprio Tribunal de Contas do Congresso (Government Accountability Office, GAO) constatou, em 2009, que a OSHA não dispunha dos controles necessários para velar pelo acordo de confiança (OSHA, 2009; GAO, 2010). Segundo os sindicatos, a redução das categorias de acidentes reconhecidos e a não-consideração dos acidentes entre os precários - frequentemente imigrantes - falseiam as estatísticas ${ }^{14}$. Em matéria de classificação abusiva de empregados como trabalhador independente, os Estados procedem por auditoria, mas inspecionam menos de $2 \%$ das empresas por ano e concentram-se nos pequenos empregadores. Em todos os casos, a sanção mínima não ultrapassa 50 dólares (Department of Labor, 2004a).

Como tornar os direitos legíveis e acessíveis aos trabalhadores precários nos Estados Unidos, as falhas que um jurista chamou de "buraco negro" do direito trabalhista (BEFORT, 2004)? Generaliza-se a fragmentação: indivíduos que trabalham em um mesmo lugar, mas em formas particulares de emprego. Além disso, os trabalhadores precários resistem à defesa coletiva dos direitos existentes, pois a maioria não tem acesso à sindicalização. À oposição entre trabalhadores com status diferentes em uma empresa se acrescenta o apelo aos trabalhadores precários como substitutos dos grevistas, prática legal e cada vez mais freqüente nos últimos vinte anos ${ }^{15}$. O trabalho precário mostrou-se assim um fator, com frequência minimizado, de fragilização do sindicalismo estadunidense, em um momento chave de sua existência, em seu papel de contra-poder.

Status salarial, acesso aos benefícios sociais, processo de precarização

Estamos diante de um duplo processo de precarização que faz do status salarial uma questão social: precarização econômica, por meio da des-

14 "Facts About Worker Safety and Health, 2005", site AFL-CIO (14 de maio de 2005).

15 Embora considerados como empregados, recusa-se regularmente aos trabalhadores em tempo parcial ou de duração determinada o direito à sindicalização pelo NLRB devido a uma insuficiente "comunhão de interesses". 
construção dos contratos coletivos; institucionalização da instabilidade, por meio de um direito trabalhista concebido para o empregado permanente.

O emprego salarial em tempo integral permanece, nos Estados Unidos, o caminho mais seguro para a obtenção dos benefícios sociais. A maioria dos empregadores propõe sempre, sem serem submetidos a restrições legais, uma fórmula de proteção social aos empregados permanentes: férias pagas, licença-saúde, cotização em um plano de aposentadoria, plano de saúde (Department of Labor, 2004b). No entanto, o número de empregados que recebem uma cobertura médica do empregador está em baixa: de 1995 a 2005, os empregados permanentes recebendo esse tipo de cobertura passaram de $74 \%$ para $71,8 \%$. Formalmente, o número de trabalhadores cobertos por um plano de aposentaria está aumentando: de 63,2\% para $65,7 \%$. Esses dados devem ser comparados com os dos trabalhadores interinos ou em tempo parcial que usufruíram, em 1995 e 2005, de um plano de saúde (22,7\% e 18,8\% respectivamente) ou de um plano de aposentadoria $(21,1 \%$ e 23,5\%) (BERGER, 1999; BLS, 2006). Às vésperas da crise, na Califórnia, somente $2 \%$ dos interinos têm um plano de saúde fornecido pelo empregador, contra 50\% dos permanentes. Dos 45 milhões de americanos que não possuem nenhuma cobertura, $80 \%$ são trabalhadores ou membros de famílias que dependem de trabalhadores que têm um emprego, mas são frequentemente precários (BERNHARDT; MARCOTTE, 2000). O desenvolvimento do trabalho precário durante a "retomada econômica sem criação de emprego" a partir de 2001 - um terço de empregos criados contra a perda de dois a três milhões de empregos industriais - explica em parte o declínio do plano de saúde ligado ao emprego do qual foi excluído um milhão de pessoas no espaço de um ano (2005), 13\% dos ex-beneficiários de 2000 a 2005 (FREEMAN; RIDGERS, 2005).

A desconstrução dos contratos coletivos nos Estados Unidos revela-se muito particularmente na transferência dos encargos para os trabalhadores, 
de todas as categorias, ou para as instituições políticas, no caso dos mais desfavorecidos. A contribuição individual do empregado está aumentando e a qualidade das prestações, diminuindo. Os benefícios assumem uma parcela cada vez maior do pacote de remunerações: de 3\% em 1929, o índice monta a 28\% aproximadamente em 2004 (THEVENARD, 2007). A proporção de trabalhadores que usufruem dos benefícios do cônjuge, assim como o recurso ao auxílio público de seguro-saúde (Medicaid) continua progredindo. Constata-se nas empresas um tratamento cada vez mais diferenciado de trabalhadores com status diferentes, privilegiando um núcleo de empregados permanentes, mais qualificados, que elas visam a estabilizar $^{16}$. Em matéria de pensões, apenas 20\% dos empregados continuavam a se beneficiar, em 2005, de um fundo tradicional por distribuição na empresa (defined benefit plans), fórmula substituída cada vez mais por contas pessoais de aplicação $\left(401 \mathrm{k}^{17}\right)$, o que acarreta a individualização, por meio da financeirização do sistema. Isso explica o aumento da proporção de trabalhadores cobertos por um plano de aposentadoria, acima mencionado.

Essa transferência dos benefícios sociais para o trabalhador individual representa a característica principal do processo de precarização (OSTERMAN, 1999). Pode-se constatar, em diferentes planos, a heterogeneidade da experiência de diferentes categorias de trabalhadores nãoassalariados: dentre os trabalhadores independentes e os contratuais de longa duração (37,4\% do conjunto dos trabalhadores precários e 62,8\% dos homens), a maioria é de homens brancos, com maior instrução, mais idade do que a média dos empregados e com remunerações elevadas. Mas o que é comum a todos os precários e que faz deles uma catego-

16 A porcentagem total de não-segurados permaneceu relativamente estável desde 2003, passando de $15,7 \%$ a 15,9\%, em função do aumento do número de beneficiários dos dispositivos públicos, em particular Medicaid. State of Working America.

17 O Plano 401 (k) é a poupança-aposentadoria com cotização de um montante de contribuição definido para o empregado e normalmente complementado pelo empregador. Seu nome refere-se à seção 401 (k) do Internal Revenue Code (Código Fiscal Nacional dos Estados Unidos). 
ria é o fato de que têm menos acesso aos benefícios sociais do que os empregados permanentes (KALLEBERG; RASSEL, 1997; CARRÉ; FERBER, 2000). Assim, a obrigação de um número cada vez maior de trabalhadores de encontrar uma solução individual dá lugar à criação de fórmulas alternativas. Surge um novo mercado privado de fornecedores ao lado dos seguros mutualistas organizados pelas associações de precários e sindicatos (NAFFE, 2005). Essa transferência marca uma modificação fundamental da relação de trabalho e não é absolutamente contraditória, como vamos ver, com a lei de 2010 sobre o plano de saúde.

Nesta reflexão sobre a precarização, devemos retomar o fenômeno mais amplo dos "subempregos". Pode-se definir essa camada como a população privada de plenos direitos do empregado. Ao pequeno terço da população ativa recenseada como precária, desde antes da recessão do final de 2007, era necessário acrescentar aos desempregados os trabalhadores desmotivados - riscados das estatísticas oficiais -, que abandonaram a busca de um emprego e, em outro plano, a população dos detentos ou que atuam no mercado negro (BELOUS, 1995; MODDELTEON, 1996). Este recobre setores bem visíveis, a ponto de serem banalizados, como o dos trabalhadores domésticos, com frequência imigrantes. O trabalho diário dos clandestinos é onipresente nesta categoria, assim como a classificação abusiva dos empregados como trabalhadores independentes, que passa pela remuneração em dinheiro líquido. O Condado de Los Angeles estimou em 1,1 bilhões de dólares anuais a perda de receitas fiscais devido ao mercado negro. É quase inexistente a regulamentação das condições de trabalho e das remunerações (Daily News, 2003).

Pode-se dissociar a existência de bolsas de precarização nos Estados Unidos do problema do acesso a um emprego permanente? E embora a população precarizada apresente grosso modo o mesmo perfil de outros países industrializados - mais mulheres, mais jovens, imigrantes, 
com pouca instrução (e uma presença significativa de superdiplomados) -, o que é específico à situação estadunidense é a extrema estratificação quanto à raça e, geograficamente, a existência de guetos étnicos (WACQUANT, 2006). Trata-se das minorias em geral, sobretudo dos negros, que não ganhavam em 2004 senão 55,6\% da renda dos brancos. Fato principal, uma família negra média capitalizava apenas 19\% das riquezas (net worth) acumuladas por uma família branca, principalmente a casa própria. É o índice mais significativo, mais do que o salário, das chances de ascensão social da próxima geração (MISHEL; BERNSTEIN, 2007).

Segundo uma comissão de inquérito do Senado americano em março de 2007, se o índice de desemprego nacional alcançava somente $4,5 \%$, o de uma camada particular, a dos homens negros sem ensino secundário, havia passado de $59 \%$ para $72 \%$ em alguns anos. A cifra equivalente era de 29\% para os brancos e de 19\% para os hispânicos. Para o presidente da comissão, o senador Charles Schumer, o problema do subemprego entre os homens negros já representava na época um problema "profundo, persistente e que deixa perplexo" (HERBERT, 2007).

Quais são as perspectivas?

Nos Estados Unidos, não faltam propostas e iniciativas - legislativas ou jurisprudenciais, sindicais ou associativas, federais ou estaduais - para remediar à desconstrução da relação de emprego e suas consequências nefastas.

No Congresso americano, foram propostos projetos de lei para: ampliar a definição do grupo social dos empregados, delimitar a definição de um trabalhador independente, permitir a transferência dos direitos adquiridos de um emprego a outro (portability), principalmente em matéria de conta de investimento para a aposentadoria. Contudo, esses projetos nunca ultrapassaram a fase das comissões. De maneira mais certeira, programas locais semipúblicos, juntamente com parceiros sociais, 
envolvem-se na formação e na inserção dos mais vulneráveis ${ }^{18}$. A proteção aos precários melhorou devido a formas alternativas de acesso aos benefícios sociais ou à implantação das agências de colocação (hiring halls), organizadas pelas associações e pelos sindicatos, como a Workinf Partnerships criada pela AFL-CIO no Vale do Silício. Ao mesmo tempo, algumas associações (Carolina Alliance for Fair employment) militam simplesmente pela aplicação das normas legais em vigor, como o pagamento do salário mínimo (WHEELER, 2002). Constata-se o início de uma sindicalização entre os universitários substitutos, entre os Permatemps da alta tecnologia, que fizeram com que se reconhecesse seu status salarial na Microsoft. Por outro lado, certos Estados são precursores na extensão dos direitos aos precários, em matéria de discriminação, de indenizações por acidente de trabalho para os imigrantes ilegais ou de sanções contra os abusos; já o grau de regulamentação das agências de trabalho interino varia enormemente. O caminho das reformas poderia passar pelo sistema jurídico e pela evolução da common law, processo flexível de arbitragem dos direitos: certas proteções contra a discriminação e o assédio foram estendidas aos trabalhadores independentes (PIRRUCCELLO, 2005).

Levantar a questão do papel do Estado federal e de uma legislação global é, em todos os casos, indispensável. A reforma do auxílio social em 1996 marcara uma virada no papel do Estado como regulador: de modo revelador, o Personal Responsability and Work Opportunity Reconciliation Act transferiu o risco para o trabalhador individual (MCGARITY, 1996). Esse recuo do intervencionismo federal desembocou em "uma geração de trabalhadoras precárias": as curvas da população operária pobre em situação de precariedade encontram agora aquelas das beneficiárias da

18 Connecticut Regional Workforce Investment Boards, disponível em: <http://www.ctdol. state.ct.us/index.htm >. 
ajuda pública temporária, que substitui o welfare $^{19}$. Essa forma de trabalho remunerado por magras quantias tende a desmantelar o emprego assalariado, mesmo em sua forma estadunidense fragmentada, a substituição de postos de trabalho privados e públicos, frequentemente sindicalizados e gozando de benefícios. Isso acontece com os funcionários dos parques públicos da cidade de Nova York, constituídos hoje em dia de três quartos de beneficiários do workfare (HEASLY, 1997, Department of Health and Human Services, 2004).

Tudo depende da existência de uma vontade de mudança e dos recursos políticos. Uma proliferação de soluções inovadoras reflete, certamente, a energia e o otimismo estadunidense (DEYSINE, 2006), mas também a asfixia do dinamismo unificador dos movimentos sociais do século XX e dos avanços, em termos de democracia política, deles oriundos. O modelo de aquisição contratual privada e descentralizada dos benefícios sociais ligado ao emprego fragiliza-os ainda mais no contexto atual. A multiplicação de benefícios individuais ou obtidos em âmbito local não leva à implantação de um sistema global e corre o risco de acarretar o apagamento do espaço nacional como espaço de direitos. Até a crise, podia-se constatar um leve reequilíbrio dos direitos em favor dos empregados, graças às câmaras e aos tribunais de certos Estados. Mas o progresso social nos Estados Unidos deu-se sobretudo em uma dinâmica de criação dos direitos provenientes das instituições nacionais (cidadania dos negros, direitos operários, direitos cívicos). Um novo federalismo poderia fortalecer a tendência histórica dos "direitos dos Estados", onde a relação de força tende a favorecer os interesses patronais. O voto de uma lei federal em 2007 sobre o aumento do salário mínimo que beneficiava principalmente os baixos salários - promessa eleitoral dos democratas durante as

19 A Temporary Assistance for Needy Families (TANF) substituiu o welfare (Aid to Families with Dependent Children) desde o Personal Responsibility and Work Opportunity Reconciliation Act de 1996, que introduziu o workfare. (DIETRICH, 1998). 
mid-term elections, eleições de meio de mandato de 2006 - restaurara, para alguns, a ideia de uma lógica de unificação do direito social nacional pela aproximação dos direitos dos Estados. Mais da metade dos Estados já havia aumentado o salário mínimo acima do nível federal (este, a 5,15 dólares a hora, correspondia ao nível mais baixo dos últimos cinqüenta anos). Ora, o novo aumento para 7,25 dólares votado pela nova maioria democrata no Congresso, em 2007, não recuperou as perdas do poder aquisitivo. Quinze Estados votaram índices acima desse mínimo federal (Department of Labor, BLS, 2007).

\section{E quanto à crise?}

Este levantamento permite apreciar melhor o impacto da crise numa situação em que quase não existia vontade política de responder à crise estrutural já iniciada pela precarização da relação de emprego. O conjunto desses dados deve ser revisto à luz da explosão da bolha financeira, em setembro de 2008, que nada mais fez do que agravá-la. O índice de desemprego nos Estados Unidos mais do que dobrou nos dois anos que se seguiram ao início da recessão em dezembro de 2007, passando de 4,9\% para 10,2\%, índice mais elevado desde 1982 (10,9\%) (Bureau of Labor Statistics, 2009). Disparidades acentuam-se com as variações de gênero e de etnia e raça. No mês de outubro de 2009, enquanto o índice dos brancos subia para $9,5 \%$, sendo $10,7 \%$ para os homens brancos, principalmente na manufatura, a média nacional dos trabalhadores hispânicos e negros era de 13,1\% e 15,7\% (BLS, 2010).

A difusão de informações enraizou nos espíritos a realidade de centenas de milhares de desempregados a mais por mês, a perda de 8,2 miIhões nesse período, alcançando 15,7 milhões ao final de 2009. Trata-se, neste caso, de índices que seguem a definição mais estrita de desempre- 
go, pois a medida mais ampla do BLS do subemprego - que acrescenta o desemprego parcial e os trabalhadores desmotivados que renunciaram à busca oficial de emprego - ultrapassava $17 \%$ da população ativa. Os primeiros atingidos foram os postos mais precários: a demissão maciça de interinos, representando um terço do emprego na manufatura, e a "criação" de novos precários devido aos tempos parciais ou a redução do número de horas trabalhadas (SAUVAIT, 2009).

A constatação de uma modificação estrutural do mercado de trabaIho já fora assinalada, no início do século, por Ben Bernanke, presidente do Banco Central dos Estados Unidos. Para o dirigente da FED, a "retomada sem criação de empregos" caracterizava-se pelos empregos de tipo não-padrão que constituíam dois terços dos empregos criados no período posterior à recessão de 2001. De acordo com pesquisadores do ramo regional do FED de Kansas City, não há muito motivo de otimismo, em um período próximo, no que tange ao emprego:

While the evidence is not conclusive, such changes in labor markets since the early 1980s appear to have produced conditions conducive to restrained, delayed hiring in the aftermath of recessions. Following the most recent two recessions, this weakness in hiring contributed to jobless recoveries. To the extent that these structural changes in the labor market have persisted through the current recession, it is distinctly possible that unemployment going forward may not decline as rapidly as it did following other severe recessions (KNOTEK; TERRY, 2009).

A resposta federal à crise foi dupla: legislação de medidas para a retomada e, embora em outro plano, a lei do plano de saúde de 2010. Sem fazer uma análise detalhada, convém levantar algumas das implicações atinentes à relação de emprego e aos direitos e benefícios associados.

Em primeiro lugar, há um intenso debate em torno dos planos de retomada econômica, principalmente a lei Obama pra a recuperação or- 
çamentária e a retomada econômica, o American Recovery and Reinvestment ACT, ARRA, de fevereiro de 2009. Para os aliados do presidente, o plano de salvação de milhões de empregos - no mínimo 3,5 milhões de empregos, precisamente - terá conseguido evitar que o índice de emprego piore, até 13\% pelo menos em 2010 (BARTIK; BISHOP, 2009; IRONS; POLLOCK, 2009). O campo conservador, um think tank influente como a Heritage Foundation, vai contra a ARRA, a começar por sua formulação em termos deliberadamente vagos e improváveis: como contabilizar o número de empregos "salvos"? Além disso, os auxílios fornecidos não traduzem uma verdadeira criação de empregos, pois só podem provir do investimento no mercado do setor privado. Trata-se de auxílios cosméticos fornecidos a indústrias periclitantes, respondendo apenas às pressões dos lobbies tradicionais do Partido Democrata, como a salvação da indústria automobilística, caracterizada aqui como não-produtiva, em nome da aliança com os sindicatos (RIEDL, Heritage Foundation, 2010).

Como não ver, neste debate politiqueiro que quase não se renova, uma verdadeira crise política? Esse desmoronamento sem precedentes desde os anos 1930, tanto nos Estados Unidos quanto praticamente em todo o mundo, em termos de recuos do PIB e de ajustes para baixo do emprego e dos salários (GAUTIÉ, 2010), não demandaria soluções inovadoras à altura do que está em jogo? Até mesmo a revista The Economist, cujo apego à livre-empresa não precisa ser demonstrado, outrora arauto da máquina americana de criar empregos, critica agora esse modelo em seu número de 5 de novembro de 2009: "Talvez a América esteja à frente dos países ricos em período de prosperidade, mas a Europa se revela mais talentosa para enfrentar a recessão" ${ }^{20}$.

20 "AMERICA may lead the rich world in periods of prosperity, but Europe has shown a greater talent for dealing with recession." 
Quanto ao plano de saúde, não analisaremos este texto complexo de 2.000 páginas, cuja maior parte será aplicada somente a partir de 2013. Até lá, muita água passará debaixo da ponte, entre outras razões, devido aos processos intentados por um número cada vez maior de Estados que contestam a legitimidade constitucional de a União obrigar os cidadãos a contratar uma cobertura médica. O futuro da lei do plano de saúde parece fadado agora à arbitragem dos tribunais a partir da votação no Estado do Missouri, em agosto de 2010, de uma lei local por meio de um referendo popular junto aos eleitores. Ela declara, de fato, a interdição de tal prerrogativa estatal, o que contradiz o dispositivo central da lei federal (COLLINS, 2010).

É importante observar, seja qual for seu futuro, que o espírito da lei histórica diz respeito a uma concepção da relação de emprego. Dentre as opções levadas em consideração, o presidente Obama recusou duas de três: aquela que teria estendido o sistema atual pela prestação obrigatória aos empregados de uma cobertura médica pelo empregador, sob pena de penalidades (play-or-pay); aquela, preferida pelos sindicatos e pela ala esquerda do partido democrata, de um sistema nacional público chamado de single payer, como já existe, por exemplo, no Canadá. Ele preferiu o plano individual obrigatório do cidadão (individual mandate), comparável ao seguro-automóvel. Assim, cada indivíduo deverá providenciar um plano, seja por meio de seu empregador, seja particularmente, sob pena de sanções financeiras por parte da agência nacional dos impostos, a IRS ${ }^{21}$. A lei não impõe às grandes empresas fornecer um plano a seus empregados. Mas, se não o fizerem, deverão pagar uma contribuição, redistribuída na alocação de um crédito de imposto às PMI-PME que optam por oferecê-

21 A penalidade, paga ao Internal Revenue Service (IRS), montaria a 750 dólares por indivíduo ou $2 \%$ de sua renda se essa soma for superior. Disponível em: <http://www.whitehouse.gov/ healthreform $>$. 
lo aos seus funcionários. Prevê-se um auxílio aos mais desfavorecidos, não em forma de atendimento, mas de subvenção para associar-se a um plano, o que lamentam muitos democratas, que esperavam, com a vitória de seu candidato, ao menos a possibilidade de optar por uma forma de segurança social pública, dita public option. No fundo, a lei se direciona para a individualização da cobertura médica, não sem vantagem para as companhias privadas de planos de saúde.

A questão em jogo na relação de emprego consiste em saber se o centro de atribuição dos benefícios sociais não se transferirá cada vez mais para o cidadão individual. Se tal processo de individualização se afirmasse, destacando cada vez mais os benefícios do emprego, várias consequências seriam possíveis. Algumas tangeriam às decisões individuais: entrar ou permanecer na população ativa, trabalhar um número maior ou menor de horas, escolher um determinado tipo de emprego. Lembremos a que ponto essas escolhas correlacionam-se, nos Estados Unidos, ao acesso ao plano de saúde: na virada do século, a grande maioria da população não idosa, compreendendo cônjuge e dependentes, ainda é coberta (de modo mais ou menos extenso) pelo seguro do empregador como uma parte da remuneração.

No quesito remuneração, alguns temem uma tendência à baixa. Segundo as estatísticas, o empregador americano que inclui no pacote um plano de seguro paga um salário médio menor e oferece menos benefícios. Mas será que o empregador que decidir não mais fornecer seguro aumentará, em compensação, o salário do empregado em questão? Uma medida controversa da lei, dentro do próprio campo político democrata, é a imposição a longo prazo dos empregados beneficiários dos planos de seguros mais generosos (Cadillac plans). Essa medida - reclamada, aliás, pelo candidato republicano John McCain nas eleições de 2008 e que se tornou o cavalo de batalha dos sindicatos contra ele - corre o risco de 
reacionar o argumento chave da sindicalização, seu poder de negociar contratos coletivos que tornem a relação de emprego mais duradoura e favorável aos empregados (AFL-ClO, 2008-2009).

Enfim, uma última hipótese concerne à modificação eventual do índice de emprego nos Estados Unidos. A eliminação do motivo de acesso ao plano de saúde poderia retardar a entrada na vida ativa ou precipitar a saída dela. Ora, o "índice elevado de emprego" é o cerne do modelo estadunidense e tornou-se um indicador para a política do emprego em todos os países. O aumento do índice de emprego afirmou-se como prioridade da Estratégia Europeia para o Emprego (SEE) na reunião de cúpula de Lisboa, principalmente para os seniores (55-64 anos) ${ }^{22}$.

\section{Conclusão}

Pode-se imaginar, diante dos dados atuais, a existência do tipo de consenso, de relação de forças sociais e políticas da época do New Deal, em condições de enfrentar os problemas da maioria. A análise do trabalho precário auxilia a esclarecer certos paradoxos da vida estadunidense: o fato de que, mesmo em período de expansão macroeconômica durante uma geração, a família média trabalhava mais para viver menos bem, enquanto aumentava o número de trabalhadores pobres. No momento em que se proclama um amplo consenso sobre a igualdade das oportunidades, a lógica insidiosa do trabalho precário mina as conquistas do movimento dos direitos cívicos baseados na inclusão social por meio do acesso ao emprego.

22 O índice de emprego de uma classe de indivíduos é calculado relacionando-se o número de indivíduos da classe com emprego ao número total de indivíduos na classe. Ele pode ser calculado sobre a população total de um país, mas na maioria das vezes limita-se à população em idade de trabalhar (geralmente definida, em comparação internacional, como as pessoas entre 15 e 64 anos), ou a uma subcategoria da população em idade de trabalhar (Europa, 2010). 
Se a era do pós-nacionalismo foi anunciada rápido demais, principalmente no mundo universitário (AZAïS, 2010), não é certo que o Estado americano esteja em condições de superar o paradoxo da globalização: permitir o funcionamento dos mercados financeiros e o comércio global, assegurando a missão democrática de proteção aos direitos fundamentais dos cidadãos graças, acima de tudo, a seu acesso ao emprego. Estamos lidando com novas formas de colocação profissional e de aquisição dos benefícios sociais ou com a institucionalização da insegurança?

\section{Precarious work and the institutional precarization in the United States}

\section{Abstract}

We analyze the institutional underpinnings of precarious work in the United States through a double process of precarization: of the traditional contractual relationship and given the fragmented institutional framework and the inadaptation of U.S. labor law. The importance of the employee status - the contractual employment relationship - for access to social rights and basic benefits is emphasized. Effects of the recent economic crisis and public policy response are discussed in conclusion.

Keywords: Labor law. Welfare. Trade unions. Employee. Contingency work. Health care.

\section{Referências}

AFL-CIO, Disponível em: < http://www.aflcio.org>, 2008, 2009.

AMERICAN MANAGEMENT ASSOCIATION. Survey: Staffing \& Structure, Summary of Key Findings. National Alliance for Fair Employement NAFFE. Disponível em: <http://www.fairjobs.org>, 1999.

APPAY, B. La Dictature du Succès: Le paradoxe de l'autonomie contrôlée et de la précarisation. Paris: L'Harmattan, 2005. 
AUTOR, D. Outsourcing at Will: The Contribution of Unjust Dismissal Doctrine to the Growth of Employment Outsourcing. Journal of Labor Economics, v. 21, n. 1, 2003.

AZAÏS, C. Labour and Employment in a Globalising World: Autonomy, collectives and political dilemmas. Bruxelles: Editions Peter Lang (à paraître), 2010.

BARTIK, T.J.; BISHOP, H. The Job Creation Tax Credit: Dismal projections for employment call for a quick, efficient, and effective response. EPI Briefing Paper, \# 248, New York: Economic Policy Institute, 20 octobre 2009. Disponível em: $<$ http://www.epi.org $>$.

BEFORT, S.F. Revisiting the Black Hole of Workplace Regulation: A Historical and Comparative Perspective of Contingency Work. Berkeley Journal of Employment and Labor Law, 2003.

BELOUS, R.S. The Rise of the Contingent Work Force: The Key Challenges and Opportunities. 52 Wash. \& Lee L. Rev. 868, 1995.

BERGER, M. The Contingent Employee Benefits Problem. 32 Ind. L. Rev. 301, 1999.

BERNHARDT, A.; MARCOTTE, D.E.. Is 'Standard Employment' Still What it Used to Be? In: CARRÉ, F.; FEBER, M. (Eds.). Nonstandard Work: The Nature of Challenges of Changing Emloyment Arrangements, IRRA, 33, 2000.

BUREAU OF LABOR AND STATISTICS (BLS). Employer Costs for Employee Compensation. 2006. Disponível em: <http://www.bls.gov/schedule/archives/ ecec_nr.htm>.

. Employment Situation Summary. Disponível em: <http://www.bls.gov/ news.release/empsit.nr0.htm>, décembre 2009.

. Employment and unemployment in families by race and Hispanic or Latino ethnicity, 2007-2008-2009, Table 1, mai 2010. Disponível em: < http:// www.bls.gov/news.release/famee.t01.htm>. archive.htm $>$.

Monthly Labor Review. Disponível em: <http://www.bls.gov/opub/mlr/

COHANY, S. R. Workers in Alternative employment arrangements. Monthly Labor Report, v. 119, n. 31, octobre 1996.

CARLSON, R. R. Why the Law Still Can't Tell an Employee When It Sees One and How It Ought to Stop Trying. Berkeley Journal of Employment and Labor Law, V. 22, n. 295, 2001.

CARRÉ, F.; FEBER, M. (Eds.) Nonstandard Work: The Nature of Challenges of Changing Emloyment Arrangements, IRRA, 33, 2000. 
Sociologias, Porto Alegre, ano 12, no 25, set./dez. 2010, p. 66-100

CHAUVIN, S. Les agences de la précarité. Journaliers à Chicago. Paris: Editions Le Seuil, 2010.

COLLINS, G. Show me Your Insiders. New York Times, 4 août 2010.

DAILY NEWS. Cash Economy Threatens Wages, Tax Base. Disponível em: < http:// www.nelp.org/>, 6 mai 2002

DEPARTMENT OF HEALTH AND HUMAN SERVICES. Fact Sheet: America's Ownership Society: Expanding Opportunities, disponível em: <http://www. whitehouse.gov/>; President Announces \$43 Million in Grants from Compassion Capital Fund: Faith and Community-Based Groups to Help Youth, Couples, Needy, 2004. Disponível em: <http://www.hhs.gov/news/press/2004pres/>,

DEPARTEMENT OF LABOR. Unemployment Insurance (UI) Performs 38, Disponível em: <http://www.workforcesecurity.doleta.gov.unemploy/>, 2004a.

. National Compensation Survey: Employee Benefits in Private Industry in the United States, disponível em: < http://www.bls.gov/ncs/ebs/sp/ebsm0002. pdf $>$, 2004b.

- Minimum Wage, disponível em: <http://www.dol.gov/whd/minwage/ america.htm >, 2007.

DERICKSON, A. Health Security for All? Social Unionism and Universal Health Insurance 1935-1938. The Journal of American History, n. 80, 1994.

DEYSINE, A. Les Etats-Unis aujourd'hui: Permanence et changements. Paris: La Documentation Française, 2006.

DIETRICH, S. Work Reform : The Other Side of Welfare Reform. Standford Law and Policy Review, v. 9, n. 53, hiver 1998.

ESTADOS UNIDOS DA AMÉRICA. GAO. U.S. Government Accountability Office. OSHA's Voluntary Protection Programs: Improved Oversight and Controls Would Better Ensure Program Quality. Disponível em: < http://www.gao.gov/products/ GAO-09-395>, 2010.

EUROPA. Employment and Social Policies. Disponível em: <http://europa.eu/ legislation_summaries/employment_and_social_policy/community_employment_ policies/index_fr.htm>, 2010.

FREEMAN, R. B.; RIDGERS III, W. M. The Weak jobs Recovery: Whatever Happened to "The Great American Jobs Machine"? FRBNY Economic Policy Review, août 2005.

GAUTIE, J. Entretiens de I'IRES, Institut de Recherches économiques et sociales. Paris, 11 février 2010. Disponível em < http://www.ires.fr>.

GONOS, G. The Contest Over «Employer» Status in the Post-War United States: The Case of Temporary Help Firms. Law \& Soc'y Rev, n. 81, 1997. 
GONOS, G. Evolution of the Law on Temporary Work in America: Employment Protection for Atypical Workers, 10, Employee Rights and Employment Policy Journal, n. 1, 2006.

GOTTSHALK, M. The Shadow Welfare State: Labor, Business, and the Politics of Health Care in the United States. Ithaca: Cornell University Press, 2001.

HANDELMAN, T. On Our Own: Strategies for Securing Health and Retirment Benefits in Contingent Employment. Symposium on the Regulatory Future of Contingent Employment. Washington and Lee Law Review, v. 54, n. 487, 1995.

HARRISON, B. Lean and Mean: the Changing Landscape of Corporate Power in the Age of Flexiblity. New York: Basic Books, 1994.

HEALY, M. N.Y. "Workfare" Not so Fair After All, Some Say. Los Angeles Times. Juillet 2007.

HERBERT, B. Danger Zone. On Our Own: Strategies for Securing Health and Retirment Benefits in Contingent Employment. New York Times, 15 mars 2007.

HOUSEMAN, S.; OSAWA, M. (Eds.) Nonstandard Work in Developed Countries: Causes and Consequences. Kalamazoo, Michigan: W.E. Upjohn Institute for Employment Research, 2003.

IRONS, J.; POLLOCK, E. The Recovery Package in Action: Economy is already benefitting, but full force of stimulus is yet to come. EPI Briefing Paper \# 239, New York: Economic Policy Institute, 13 août 2009. Disponível em: <http://www.epi.org>.

JACOBY, W. Imitation and Politics: Redesigning Modern Germany. Ithaca: Cornell University, 2001.

KALLEBERG,A.L.; RASELL, E. (Eds.) Nonstandard work, Substandard Jobs: Flexible Work Arrangements in the U.S. Economic Policy Institute, EPI Study. New York: Economic Policy Institute, septembre 1997. Disponível em < http://www. epi.org $>$.

KNOTEK, E. S. II; TERRY, S. How Will Unemployment Fare Following the Recession? Economic Review, Federal Reserve Bank of Kansas City, octobre 2009. Disponível em: <http://www.kansascityfed.org/Publicat/EconRev/PDF/09q3knotek.pdf>.

KOCHAN, T.; SHULMAN, B. A New Social Contract: Restoring Dignity and Balance to the Economy. EPI Briefing Paper no. 184. New York: Economic Policy Institute, 22 février 2007. Disponível em: <http://www.epi.org>.

LEFRESNE, F. Le contrat de travail en question. In: Batailles pour I'emploi, Regards sur l'actualité, no. 324, La Documentation française, octobre 2006.

LICHTENSTEIN, N. (Ed.) Wal-Mart: The Face of 21st Century Capitalism. New York: The New Press, 2005. 
Sociologias, Porto Alegre, ano 12, no 25, set./dez. 2010, p. 66-100

MCGARITY, T. O. The Expanded Debate Over the Future of the Regulatory State. University of Chicago Law Review, v. 63, n. 1463, autumn 1996.

MERCHANT, J. Are Women Protected in the Workplace? Sexual Harassment: the Case of Temporary and Undocumented Workers. Contribution colloque "Doits et movement social", organise par Donna Kesselman à I'Université Paris Ouest Nanterre La Défense, 2005.

MIDDLETON, J. Contingent Workers in a Changing Economy: Endure, Adapt, or Organize? New York University Review of Law and Social Change, v. 22, n. 3, 1996.

MISHEL, L.; BERNSTEIN, J.; ALLEGRETTO, S. The State of Working America: 2006/2007. Ithaca: Cornell University Press, Economic Policy Institute, 2007.

MONTHLY LABOR REVIEW, v. 128, n. 8, août 2005.

MOSS, P.; SALZMAN, H.; TILLY, C. Limits to Market-Mediated Employment: From Deconstruction to Reconstruction on Internal Labor Markets. In: CARRÉ, F.; FEBER, M. (Eds.) Nonstandard Work: The Nature of Challenges of Changing Emloyment Arrangements, IRRA, 33, 2000.

NAFFE, National Alliance for Fair Employement, septembre 2005. Disponível em: <http://www.fairjobs.org/report/fightback.php>.

NELP, National Employment Law Project. Disponível em: < http://www.nelp. $\operatorname{org} />$.

NLRB, National Labor Relations Board. Disponível em: <http://www.nlrb.gov>.

OSHA, Occupational Safety and Health Administration. Voluntary Protection Programs (VPP): An OSHA Cooperative Program, 2010. Disponível em: < http:// www.osha.gov/dcsp/vpp/>.

OSTERMAN, P. Securing Prosperity: The American Labor Market: How it has. Changed and What to Do about it. Princeton, NJ: Princeton University Press, 1999.

PELISSIER, J; SUPIOT, A. Droit du travail. Paris: Dalloz, 2006.

PIRRUCCELLO, J. E. Contingent Worker Protection From Client Company Discrimination: Statutory Coverage, Gaps, and the Role of the Common Law. Texas Law Review, v. 84, n. 19, novembre 2005.

PR NEWSWIRE, 20 décembre 2001, Disponível em: <http://www.prnewswire. cOm $>$.

PERUSEK, G.; WORCESTER, K. (Eds.) Trade Union Politics. American Unions and Economic Change, 1960s-1990s. Atlantic Highlands, New Jersey: Humanities Press, 1995. 
RIEDL, B. White House Report Claims Stimulus Success - Despite 3.5 Million Job Losses. American Heritage Institute, 14 janvier 2010. Disponível em: < http:// www.heritage.org/Research/Reports/2010/01/White-House-Report-Claims-Stimulus-Success-Despite-3-Million-Job-Losses $>$.

RUCKELHAUS, C. K. Providing Fairness to Workers Who Have Been Misclassified as Independent Contractors, auprès de la Commission sur l'éducation et le travail du Congrès, National Employment Law Project, NELP, 27 mars 2007.

. Summary of Independent Contractor Reforms, State and Federal Activity. National Employment Law Project, juillet 2008. Disponível em: < http://www. nelp.org $>$.

SAUVIAT, C. A crise sans précédent, mesures sans précédent mais business as usual. Chronique internationale de I'IRES. Paris: Institut de recherches économiques et sociales, novembre 2009. Disponível em: <http://www.ires-fr.org/>.

SCHÖMANN, I.; SCHÖMANN, K. In Search of a New Framework for Flexibility: Reregulation of Nonstandard Employment in the European Union. In: HOUSEMAN, S.; OSAWA, M. (Eds.) Nonstandard Work in Developed Countries: Causes and Consequences. Kalamazoo, Michigan: W.E. Upjohn Institute for Employment Research, 2003.

STONE, K. V. W. From Widgets to Digits: Employment Regulations for the Changing Workplace. Cambridge: Cambridge University Press, 2004.

. Legal Protections for Workers in Atypical Employment Relationships in the United States. XVIII Congrès mondial du droit du travail et de la sécurité sociale, 2006

THEVENARD, Evelin. Travail et droits sociaux: le déclin de la couverture maladie liée à l'emploi. Revue Française d'Etudes Américaines, n. 111, 2007/1.

WACQUANT, L. Parias urbains: Ghetto, banlieues, Etat. Paris: La Découverte, 2006.

WHEELER, H.; HOYT N. Wheeler. The Future of the American Labor Movement, Cambridge: Cambridge University Press, 2002.

WIATROWSKI, W.J. Medical and retirement plan coverage: exploring the decline in recent years. Monthly Labor Review, v. 127, n. 8, août 2004.

Recebido: 08/07/2010

Aceite final: 09/08/2010 